Objectives: To analyze the incidence and trend of hospital admissions for CVDs in patients with RA in Spain during the period between 1999 and 2015.

Methods: We performed an observational retrospective population study analyzing the spanish administrative database that includes a Minimun Basic Data Set (MBDS) of hospital admissions of patients with RA 1999-2015. We selected the MBDSs for CVDs, myocardial infarction (MI), ischemic heart disease (IHD), congestiveheart failure (CHF), cerebrovascular disease (CeVD) and aortic aneurysm (AA). Cases were identified by the presence in primary and secondary diagnosis of ICD9 codes. The population at risk was estimated through the population censuswith an estimated prevalence of RA of $0,5 \%(0,8 \%$ women, $0,2 \%$ men). Crude and adjusted rates were calculated, and the trend was analyzed using the Generalized Linear Model (GLM) with the year as the analysis variable. SPSS statistical package version 20 (SPSS Inc, Chicago, IL) was used.

Results: 338.343 RA hospital admissions were detected in the period, being $207.597(61,3 \%)$ due to CVDs. table1 summarizes the data of the six subgroups of CVDs.

Conclusions: CVDs were the first cause of hospital admissions in Spain in RA patients during the period 1999-2015. Moreover, in that period there was an increasing incidence of hospital admissions due to CVDs in all the studied subgroups, being strikingly higher inmen after age-adjusted rates. An annual rate increase is estimated in all the different studied subgroups oscilating between 5 and $9 \%$ annual increasing.

\begin{tabular}{|c|c|c|c|c|c|c|}
\hline & $\begin{array}{c}\text { Cardiovascular } \\
\text { disease }\end{array}$ & $\begin{array}{l}\text { Myocardial } \\
\text { Intarction }\end{array}$ & $\begin{array}{l}\text { Ischemic heart } \\
\text { disease }\end{array}$ & \begin{tabular}{|c|c|c|c|c|c|c|c|c|c|} 
Coneeart \\
fallure
\end{tabular} & $\begin{array}{c}\begin{array}{c}\text { Cerebrovascular } \\
\text { disease }\end{array} \\
\text { dise }\end{array}$ & \begin{tabular}{|l|l} 
Aortic aneurysn \\
\end{tabular} \\
\hline 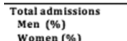 & $\begin{array}{c}207597 \\
7724(34.5) \\
13583(65)\end{array}$ & 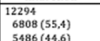 & $\begin{array}{c}37699 \\
19945(52,6) \\
1734640)\end{array}$ & \begin{tabular}{|l|l|}
317655 \\
$9970(31,4)$ \\
21795686
\end{tabular} & 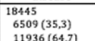 & $\begin{array}{l}2144 \\
1992(69,6) \\
652(300)\end{array}$ \\
\hline $\begin{array}{l}\text { Women }(\%) \\
\text { Mean age (SD) }\end{array}$ & 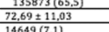 & $\begin{array}{l}5486(444,6) \\
72,24 \pm 10,38 \\
1.60 .95)\end{array}$ & 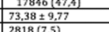 & 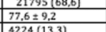 & 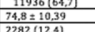 & \begin{tabular}{|l}
$652(30.4)$ \\
$74.52 \pm 9.06$ \\
20.595
\end{tabular} \\
\hline 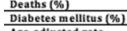 & $\frac{1969(1)}{39639(19,1)}$ & $2971(24,2)$ & $\frac{2818(7,5)}{9404(25)}$ & \begin{tabular}{|l}
$62681(2,3)$ \\
$661(21)$
\end{tabular} & $\frac{2582(12,3)}{3746(20,3)}$ & $\mid \frac{04(0,5)}{258(12)}$ \\
\hline $\begin{array}{l}\text { Age-adjusted rate } \\
\text { Men } \\
\text { Mon }\end{array}$ & $\begin{array}{c}7407.36 \\
\text { 13275.48 } \\
532305\end{array}$ & $\begin{array}{l}440.02 \\
1426,00 \\
23740\end{array}$ & $\begin{array}{l}1348.85 \\
3655.64 \\
77292\end{array}$ & $\begin{array}{c}1151.125 \\
1873,95 \\
05036\end{array}$ & $\begin{array}{l}664,11 \\
1211.71 \\
5158\end{array}$ & $\begin{array}{c}322,88 \\
1425.31 \\
116.63\end{array}$ \\
\hline $\begin{array}{l}\text { Age-aicusted rate } \\
\text { g }\end{array}$ & $3795,03 \rightarrow 9070,71$ & $212,71 \rightarrow 553,56$ & $680,78 \rightarrow 1776,24$ & $542,62 \rightarrow 1739,70$ & $350,13 \rightarrow 934,61$ & 30 \\
\hline $\begin{array}{l}\text { Men } \\
\text { Men } \\
\text { Women }\end{array}$ & $\begin{array}{l}6499,91 \rightarrow 18200,19 \\
30391 \rightarrow \rightarrow 7093,63\end{array}$ & $599,73 \rightarrow 1527,98$ & $1704,03 \rightarrow 4769,41$ & $868,77 \rightarrow 2889,88$ & $\begin{array}{l}619,66 \rightarrow 1710,68 \\
\rightarrow\end{array}$ & $115,07 \rightarrow 437,35$ \\
\hline 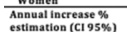 & 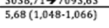 & 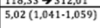 & \begin{tabular}{|l|}
$2525,63 \rightarrow 1932,64$ \\
$5,28(1,044-1,062)$
\end{tabular} & 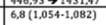 & $\frac{27,617+131,72}{6.3(1,054 \cdot 1,072)}$ & \begin{tabular}{|l}
$0,10 \rightarrow 55,83$ \\
$9,1(1,076-1,107)$
\end{tabular} \\
\hline $\begin{array}{l}\text { verisk } \\
\text { womer }\end{array}$ & 2.28 & 5,33 & 4,7 & 1.97 & 2.36 & \begin{tabular}{|l}
12.2 \\
\end{tabular} \\
\hline
\end{tabular}

Disclosure of Interest: None declared

DOI: 10.1136/annrheumdis-2018-eular.4278

\section{SAT0130 IMPROVEMENT OF NUTRITIONAL CONDITIONS IN PATIENTS WITH RHEUMATOID ARTHRITIS STARTING FIRST DISEASE MODIFYING ANTI-RHEUMATIC DRUGS}

D. Kobayashi ${ }^{1,2}$, S. Ito ${ }^{2}$, E. Hasegawa ${ }^{1,2}$, I. Narita ${ }^{1}$, K. Nakazono ${ }^{2} .{ }^{1}$ Division of Clinical Nephrology and Rheumatology, Niigata University Graduate School of Medical and Dental Sciences, Niigata; ${ }^{2}$ Rheumatology, Niigata Rheumatic Center, Shibata, Japan

Background: Rheumatoid arthritis(RA) is a chronic inflammatory condition, and has been associated with adecreased life expectancy. Although life expectancy has improved in many RA patients recently, the reason for this is not entirely clear. Objectives: We hypothesized that better disease activity control of RA led to relief from chronic inflammation, which resulted in better nutritional conditions, and contributed to a longer life expectancy. The aim of this analysis was to examine the relationship between RA disease control and the improvement of nutritional conditions.

Methods: We analyzed data obtained from 111 patients with RA (male 44, female 67 ) who were referred to our hospital and received first disease modifying antirheumatic drugs (DMARD) in 2016 and 2017, retrospectively. The patient data were obtained retrospectively from medical records for a 6-month period starting at the date DMARDs were initiated. We chose serum albumin (Alb), total lymphocyte count(TLC), and hemoglobin $(\mathrm{Hb})$ concentration, as the indicators of the nutritional condition. Furthermore, D-values and nutrition index 40 (N.I.40), indicators of anastomotic leakage after gastrointestinal surgery were also analyzed. Comparisons between the two groups were performed using Mann-Whitney U test. Comparisons between the parameters at different time points were performedusing Wilcoxon signed-rank test. The association among the ordered European League Against Rheumatism (EULAR) response rate and the magnitude ofimprovement in the nutritional condition were analyzed by using the JonckheereTerpstratest. Data on each patient's age and duration of RA were calculated as median $\left(\mathrm{IQR}_{1 / 4-3 / 4}\right)$ values.

Results: The patient age was 64.0 (54.0-74.5) years, and the duration of RA was 3.0 (1.0-7.0) months. Oral prednisolone (PSL) was used in 51 patients. Other drugs administered to patients over the 6-month period included: methotrexate (63 patients), iguratimod (42 patients), bucillamine (29 patients), sulfasalazine (25patients), tacrolimus (6 patients), and bDMARD (13 patients). The level of Creactiveprotein (CRP) and the disease activity score for 28 joints based on theerythrocyte sedimentation rate (DAS28-ESR) before and 6 months after the initiation of DMARD treatment improved from $0.50(0.12-1.7) \mathrm{mg} / \mathrm{dL}$ to $0.10(0.010-0.20)$, $p<0.001$, and from 4.62 (3.51-5.52) to 2.52 (1.53-3.13), $p<0.001$, respectively. The EULAR good response was achieved in 59 patients, and moderate response was achieved in 31 patients. Serum Alb level, Hb concentration, D-value, and N.I.40 showed significant improvement 6 months after the starting of DMARD [3.9 (3.6$4.3)$ vs $4.2(4.0-4.5) \mathrm{mg} / \mathrm{dL}, p<0.001 ; 12.5(11.7-13.4)$ vs $12.6(11.8-13.6) \mathrm{g} / \mathrm{dL}$ $p=0.0164 ; 0.155(-0.47-0.91)$ vs $-0.26(-0.72-0.18), p<0.001 ; 47.2(41.8-51.1)$ vs $49.8(46.1-52.2), p<0.001$,respectively]. Furthermore, we found a significant trend towards improvement of serum Alb level, $\mathrm{Hb}$ concentration, D-value, and N.I. 40 in patients with a better EULAR response ( $p$ value for trend $=0.0124,0.033$, 0.0057 , and 0.0040 , respectively).

Conclusions: There was a statisticallysignificant trend towards better nutritiona improvement in patients with a better EULAR response. Control of RA may contribute not only to joint deterioration prevention, but may also help to improve the nutritional condition of patients.

Disclosure of Interest: None declared

DOI: 10.1136/annrheumdis-2018-eular.2664

\section{SAT0131 THE ROLE OF ULTRASOUND FOR THE ASSESSMENT OF PATIENTS WITH ACTIVE RHEUMATOID ARTHRITIS}

S. Farietta ${ }^{1}$, E. Castillo ${ }^{1}$, D. Buitrago-Garcia ${ }^{2}$, L. Villarreal ${ }^{3}$, P. Santos-Moreno ${ }^{4}$. ${ }^{1}$ Ultrasound, Biomab, Center For Rheumatoid Arthritis, Bogota; ${ }^{2}$ Epidemiology, SIIES; ${ }^{3}$ Health services; ${ }^{4}$ Rheumatology, Biomab, Center For Rheumatoid Arthritis, Bogota, Bogota, Colombia

Background: Rheumatoid arthritis(RA) a chronic systemic connective tissue dis ease, one of the main symptoms is inflammation that is mainly present in hands and feet. The evaluation and follow-up of disease activity relies on composite indexes with clinical outcomes. However, many studies have shown there are differences between disease activity measured by clinical examination and ultrasound findings(1).

Objectives: The aim of this study was to evaluate the utility of ultrasound in patients with RA stratified as moderate or severe disease activity based on DAS28.

Methods: We performed across-sectional study including patients with RA patients were followed-upunder T2T standards and a multidisciplinary approach. Clinical follow-up was designed by the authors according to DAS28 as follows: every $3-5$ weeks (DAS28 $>5.1$ ), every $7-9$ weeks (DAS28 $\geq 3.1$ and $\leq 5.1$ ), and every $11-13$ weeks (DAS28 <3.1). Additionally the patient was evaluated by a rheumatologist expert in ultrasound; US studies were carried out with a Esaote MyLab Seven ${ }^{\circledR}$ US equipment (Biomedica, Genoa,Italy) equipped with a 10-18 $\mathrm{MHz}$ linear transducer; PD was adjusted according to the following parameters: frequency, 8.0, PRF, 0.500, wall filter 3 , gain between 50 and 70 . The rheumatologist reported erosions, synovitis, osteophytesand power Doppler; we defined as active disease when patients had synovitis orpositive power Doppler. We calculated means, and standard deviations for continuous variables and categorical variables were presented as rates. We performed a bivariate analysis using Pearson's $\mathrm{Chi}^{2}$

Results: 272 patients meet the inclusion criteria; most of patients were woman $87 \%$, mean age were 57 years \pm 11 , mean DAS was $4.45 \pm 1.1,70 \%$ of patients were in moderate disease activity (MDA), and 30\% in severe disease activity (SDA), $81 \%$ of patients were receiving conventional DMARDs therapy and $19 \%$ biological therapy. Regarding the findings of the ultrasound, the most prevalent elementary lesions in hands and feet were erosions, $75 \%$ and $6 \%$ see table 1. Active disease was found in $66 \%$ ( $11 \%$ of patients had only synovitis and $55 \%$ had synovitis plus Doppler) see table 2 . Thus, in patients where we assumed that had MDA or SDA, by ultrasound we found that $34 \%$ did not have disease activity. We did not find statistical association between ultrasound and age, sex or type of pharmacological therapy.

\begin{tabular}{lllll}
\hline & PRESENT & & ABSENT & \\
\hline VARIABLE & $\mathrm{n}$ & $\%$ & $\mathrm{n}$ & $\%$ \\
\hline HANDS & & & & \\
SYNOVITIS & 181 & 67 & 91 & 33 \\
POWER & 152 & 56 & 120 & 44 \\
DOPPLER & & & & 25 \\
EROSIONS & 204 & 75 & 68 & 60 \\
OSTEO & 108 & 40 & & \\
PHYTES & & & &
\end{tabular}

\begin{tabular}{lllll}
\hline FEET & & & & \\
\hline SYNOVITIS & 9 & 4 & 263 & 96 \\
POWER DOPPLER & 5 & 2 & 267 & 98 \\
EROSIONS & 16 & 6 & 256 & 94 \\
OSTEOPHYTES & 19 & 7 & 253 & 7 \\
\hline
\end{tabular}

Conclusions: In RA patients with moderate or severe disease activity ultrasonography can complement the clinical evaluation, since there are a third of patients without disease activity according to ultrasound findings; where by there is a need 